\title{
Umbilical Cord Cutting Triggers Hypertriiodothyroninemia and Nonshivering Thermogenesis in the Newborn Lamb
}

\author{
J. SACK, M. BEAUDRY, P. V. DelAMATER, W. OH, AND D. A. FISHER ${ }^{(29)}$ \\ Department of Pediatrics, UCLA Schooi of Medicine, Harbor General Hospital, Torrance, California
}

\section{EXTRACT}

The present studies in the newborn sheep were undertaken to further clarify the mechanism or mechanisms responsible for the early increases in serum thyroid hormone concentrations in the newborn as well as the significance of these changes to newborn nonshivering thermogenesis. Six groups of animals were studied to determine the influence of neonatal cooling, cord cutting, and the effects of thyrotropin-releasing hormone (TRH) and triiodothyronine (T3) injections.

Group I newborns were delivered into room air with immediate cord cutting. Group II animals were delivered into room air and cord cutting was delayed $60 \mathrm{~min}$. Group III animals were delivered into a $39^{\circ}$ water bath and maintained for $60 \mathrm{~min}$ with the umbilical cord intact; the cord was cut at the time of removal from the water bath. Group IV animals were handled similarly to group $I I I$ animals except that cord cutting was delayed $60 \mathrm{~min}$ after removal from the water bath. Group $V$ and $V I$ newborns were handled similarly to group $I V$ animals except that TRH (group $V$ ) or T3 (group $I V$ ) was injected at the time of removal from the water bath. Deep rectal temperature and serum free fatty acids (FFA), thyroxine (T4), and T3 concentrations were measured in all newborns; FFA was measured as an index of catecholamine release. Serum thyroid-stimulating hormone (TSH) was measured in newborns from groups $I$ and $I I$.

The results indicate that the newborn lamb responds to par turition similarly to the human newborn. There are marked increases in mean serum $\mathrm{T} 3(50-242 \mathrm{ng} / 100 \mathrm{ml})$ and FFA levels (245-744 $\mu \mathrm{Eq}$ /liter) during the first $60 \mathrm{~min}$ with only a transient fall in body temperature $\left(39.1^{\circ}\right.$ to $\left.37.4^{\circ}\right)$, indicating effective nonshivering thermogenesis. Serum $\mathrm{T} 4$ concentrations do not increase significantly during this time. Warming in the water bath (groups $I I I$ and $I V)$ prevented the FFA and $\mathrm{T} 3$ responses, indicating that parturition per se is not the stimulus to these events. Delayed cord cutting (groups $I I$ and $I V$ ) produced marked hypothermia (to 35.6 and $34.4^{\circ}$ ), and the increases in serum FFA and T3 concentrations were not observed until the cord was cut.

Mean baseline serum TSH concentrations were 4.7 and 5.3 $\mu \mathrm{U} / \mathrm{ml}$, respectively, in groups $I$ and $I I$ animals and increased modestly to peak values at $30-60 \mathrm{~min}$ whether or not the umbilical cord was cut. TRH ( group VI) did not increase serum T3 levels during the first $60 \mathrm{~min}$, but a significant 4-hr response (to $336 \mathrm{ng} / 100$ ml) was observed. T3 (group $V I$ ) did not stimulate the FFA or thermogenic responses directly, but significantly augmented both responses to cord cutting. In addition, there was a significant correlation between serum FFA or $\mathrm{T} 3$ concentrations 60 min after cord cutting and minimal rectal temperature $(r=0.53$ and 0.71 , respectively; $P<0.005$ ).

The present results indicate that in the newborn sheep: (I) umbilical cord cutting, rather than cooling, stimulates FFA release, T3 production, and nonshivering thermogenesis; (2) that the early T3 response is not mediated via TRH and TSH, but probably represents increased peripheral monodeiodination of $\mathrm{T} 4$ to $\mathrm{T} 3$; and
(3) catecholamine and T3 probably both play a significant role in newborn nonshivering thermogenesis.

\section{Speculation}

The present studies indicate that umbilical cord cutting, rather than cooling, is the stimulus to increased FFA and T3 production and nonshivering thermogenesis in the newborn sheep. The FFA response presumably reflects increased catecholamine secretion. The $\mathrm{T} 3$ response probably is due to increased monodeiodination of T4 to T3, and there is preliminary evidence to suggest that this might be mediated by stimulation of tyroxine hydroxylase activity. Thus, increased catecholamine secretion and $T 3$ production, both of which promote nonshivering thermogenesis, might be mediated via adrenergic nervous system stimulation. The mechanism for this stimulation by cord cutting, however, is not yet clear. The present studies also suggest that there are two mechanisms for the thyroidal hyperactivity in response to parturition; an early increase in T3 production due to augmented monodeiodination of T4 to T3; and increased thyroid hormone secretion, mediated by TSH, which more gradually increases serum T4 and T3 concentration during the first $24 \mathrm{hr}$ of extrauterine life.

With the events of parturition, the human newborn infant is transformed from a state of relative $\mathrm{T} 3$ deficiency to a state of hypertriiodothyroninemia. This increase in serum T3 concentration occurs very rapidly; during the first hour after delivery, serum T3 increases $300-400 \%$ with peak levels observed at about $24 \mathrm{hr}$ of age (14). Serum T4 concentrations increase more gradually to peak values at $24-48 \mathrm{hr}$ of age $(1,2,14,17,18)$. These increases in serum thyroid hormone concentrations are thought to be due to the TSH surge which occurs soon after birth. Serum TSH concentrations increased from cord blood levels to peak values of $80-90$ $\mu \mathrm{U} / \mathrm{ml}$ at $30 \mathrm{~min}$ falling gradually to baseline cord blood levels by $48-72 \mathrm{hr}(9,18)$. Data indicating that cooling of the newborn augments serum TSH and T4 levels relative to control values in infants kept in a warm environment $(17,18)$ suggest that cooling of the newborn in the extrauterine environment may be an important stimulus for the TSH surge. However, the fact that early warming does not prevent the increase in serum TSH or T4 suggests that other factor(s) might be involved $(17,18)$.

The physiologic significance of the transient hyperthyroid state in the newborn also is not clearly understood. There is a correlation between the increase in thyroid hormone levels after birth and the augmented catecholamine secretion $(14,16)$. Moreover, there is an increased sensitivity of the newborn to exogenous norepinephrine thermogenesis during the first week of life $(16,20$, 21). These observations and earlier data indicating that thyroid hormones potentiate catecholamine thermogenesis (24) and catecholamine-mediated mobilization of FFA from body fat stores (22) suggest that thyroid hormones, as well as catecholamines, 
may contribute importantly to newborn nonshivering thermogenesis.

The present studies were undertaken to further clarify the mechanism or mechanisms responsible for the early increases in serum thyroid hormone concentrations in the newborn as well as the significance of these changes to newborn nonshivering thermogenesis. The newborn sheep has been used as a model.

\section{MATERIALS AND METHODS}

Date-bred pregnant ewes (Columbia Suffolk cross) were maintained on baled alfalfa until close to term (145-150 days gestation), then separated into six different study groups.

Group I (control group) included eight newborn lambs, mean gestational age 143 days, mean weight $3.1 \mathrm{~kg}$. Two were born spontaneously into room air $\left(20-22^{\circ}\right)$; six were delivered by cesarean section under local anesthesia, also into room air $\left(20-22^{\circ}\right)$. Blood samples were obtained at delivery from lambs delivered spontaneously. Since the responses were similar in these two groups, the results have been pooled. Femoral artery catheters were inserted 30 min before delivery in lambs delivered by cesarean section. Thereafter, samples were collected at delivery and at 15-30-min intervals through $240 \mathrm{~min}$. The catheter was flushed with $37^{\circ}$ normal saline solution to replace the blood withdrawn. In all lambs the cord was cut immediately; in three newborns, deep body temperature was measured by an indwelling rectal probe and recorded at 10 -min intervals.

Group II included four lambs, mean gestational age 144 days and mean weight $3.7 \mathrm{~kg}$. These lambs were delivered into room air $\left(20-22^{\circ}\right) 30$ min after a femoral artery catheter had been inserted. The umbilical cord was left intact and covered with maternal omentum or warmed saline packs so that the blood supply to the fetus was not disturbed. The fetal face was covered with a warm saline-filled glove. As soon as the cord was cut the glove was removed. Temperature measurements and blood sampling were conducted as in the control animals. In these newborns serum $\mathrm{pH}$, $\mathrm{pO}_{2}$, and $\mathrm{pCO}_{2}$ were also measured on each blood sample.

Group III included three lambs, mean gestational age 150 days, mean weight $3.7 \mathrm{~kg}$. These were delivered by cesarean section into a constant temperature water bath $\left(39-40^{\circ}\right)$ and placed on the operating table next to the dam. Under local anesthesia the uterus was exposed through an abdominal wall incision. One fetal hindleg was delivered and immediately covered with a rubber glove filled with warm $\left(39^{\circ}\right)$ normal saline. A polyethylene catheter was inserted into the femoral artery and the hindleg replaced in the uterus. Thirty minutes later a blood sample was obtained and the lamb was delivered immediately into the warm water bath and the head was covered with a rubber glove. Deep rectal temperature was monitored using a rectal probe inserted at least $9 \mathrm{~cm}$; another probe was attached to the skin. Temperatures were recorded every $10 \mathrm{~min}$. The umbilical cord was maintained as in group $I I$ animals. Blood was sampled via the femoral artery catheter every 15-30 min; the amount withdrawn was replaced by sterile normal saline solution warmed to $37^{\circ} . \mathrm{pH}$ and $\mathrm{pO}_{2}$ were measured in each blood sample to insure that metabolic homeostasis was maintained while the animals were in the water bath. Sixty minutes later the lambs were delivered out of the water bath into room air $\left(20-22^{\circ}\right)$, the cord was cut, and the lambs were resuscitated, if necessary, and observed carefully. Temperature monitoring and blood sampling were continued.

Group IV included 9 lambs, mean gestational age 143 days and mean weight $4.3 \mathrm{~kg}$. These lambs were delivered into a warm water bath, left for 60 minutes, and removed to room air $\left(20-22^{\circ}\right)$ as described for group III animals. In contrast to group III animals, however, the umbilical cord was not cut. Special precautions were taken to keep the cord moist. The umbilical vessels remained filled and were pulsating normally. The fetal face was covered with a warm saline-filled glove which was removed at the time of cord cutting. $\mathrm{pH}$ and $\mathrm{pO}_{2}$ were monitor during the period in the water bath and for another 60 -min interval outside the water bath before cord cutting. After the cord was cut (120 min after delivery) the lambs were observed and monitored as described for group III animals.

Group $V$ included four lambs, mean gestational age 146 days and mean weight $4 \mathrm{~kg}$. These lambs were delivered and studied as group IV animals. The only difference was that $60 \mathrm{~min}$ after delivery, just before each lamb was taken out of the warm water bath, $250 \mu \mathrm{g}$ TRH (Schwarz/Mann) dissolved in sterile, normal saline were injected via the jugular vein.

Group VI included four lambs, mean gestational age 147 days and mean weight $3.3 \mathrm{~kg}$. These lambs were delivered, monitored, and studied similarly to group IV animals. However, $5 \mu \mathrm{g}$ T 3 were injected via the jugular vein at the time of delivery into room air.

Thyroxine and triiodothyronine were measured in all animals by radioimmunoassay using anilinonapthalene sulfonic acid to block protein binding by thyroxine-binding globulin $(6,7)$. FFA was measured using the extraction method of Dole (12). Ovine TSH was measured in serum of animals in groups $I, I I$, and $I I I$ using a heterologous (bovine) radioimmunoassay system and labeled bovine TSH $\beta$ chain to avoid $\mathrm{LH}$ cross-reaction. $\mathrm{pO}_{2}, \mathrm{pCO}_{2}$, and $\mathrm{pH}$ were measured using a Corning blood gas analyzer.

\section{RESULTS}

Rectal temperature data from groups $I, I I, I I I$, and $I V$ animals are depicted in Figure 1. In control lambs, delivered into room air, the cord was cut immediately. In these animals, mean rectal temperature fell from $39.1^{\circ}$ at birth to a nadir of $37.4^{\circ} 40$ min after delivery and thereafter was maintained at approximately $38^{\circ}$. Shivering was recorded between 7 and $15 \mathrm{~min}$ after delivery in each animal. In group $I I$ animals (cord cutting delayed) mean rectal temperature decreased from $39.4^{\circ}$ to $35.6^{\circ}$ within 35 min after the lambs were exposed to room air, but hypothermia progressed in

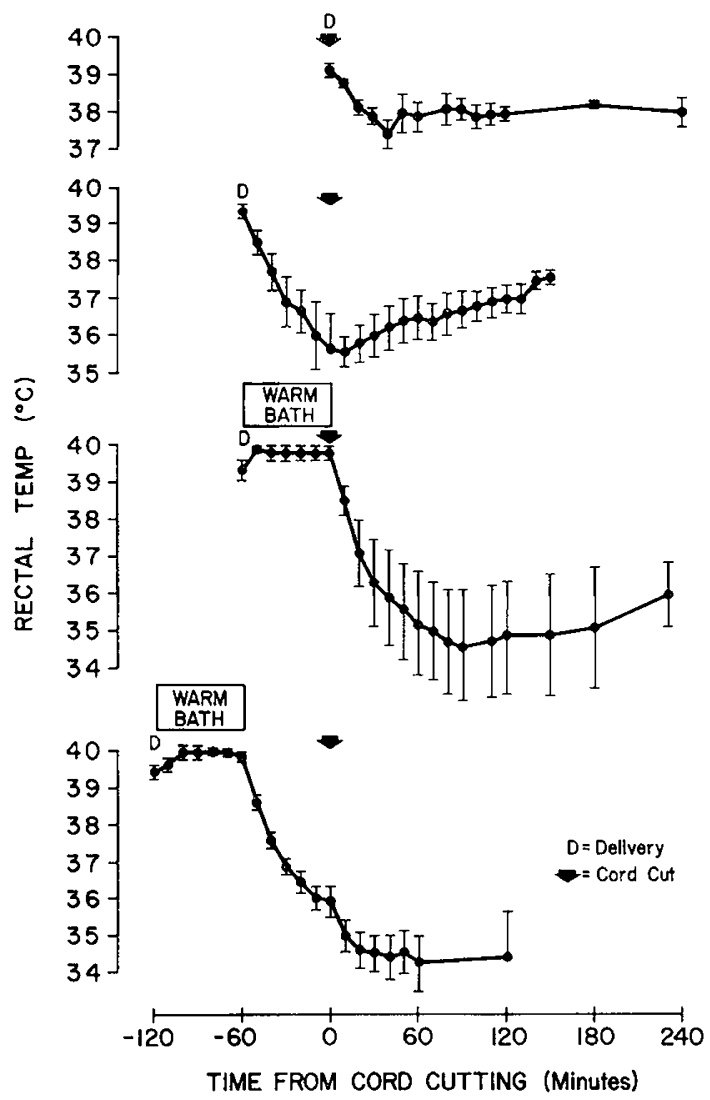

Fig. 1. Rectal temperature data from groups $I, I I, I I I$, and $I V$ animals. The solid circles $(\bullet)$ represent the mean and the bars the SEM values. The temperature curves are displayed so that zero time in all groups represents cord cutting. Details of the several group protocols are explained in text. 
spite of the shivering. Only after cord cutting was there a gradual elevation of mean rectal temperature (to $37.6^{\circ}$ ). Respiratory movements were observed in two of four animals, but ventilation was ineffective because of the saline-filled glove covering the fetal face.

Group III lambs maintained their body temperatures while they were kept in the warm water bath. However, when exposed to room air, they experienced a marked and continuous fall in mean rectal temperature (from $39.8^{\circ}$ to a nadir of $34.6^{\circ}, 90$ min after cord cutting), followed by a gradual rise to a mean of $36^{\circ}$. Shivering was observed in these animals between 7 and $30 \mathrm{~min}$ after removal from the water bath. In group $I V$ animals (delivered into a warm water bath and then into room air with cord cutting delayed $60 \mathrm{~min}$ ), rectal temperature was maintained in the water bath; exposure to room air evoked a marked fall in mean rectal temperature (from $39.9^{\circ}$ to $34.4^{\circ}$ ) which was not attenuated until 20-30 min after cord cutting. Two of these lambs died with severe hypothermia.

Serum T4 concentration data for newborns of groups $I-I V$ are presented in Figure 2. The mean (and SEM) T4 concentration in group $I$ animals increased from $8.6 \pm 1.4 \mu \mathrm{g} / 100 \mathrm{ml}$ to $12.8 \pm 2.4$ $\mu \mathrm{g} / 100 \mathrm{ml}$ at $60 \mathrm{~min}$ after delivery and cord cutting. The subsequent slight decrease in mean values is not significant. In group II newborns there was no change in the mean T4 concentration as long as the cord was intact; after cord cutting, there was a slow rise in mean $\mathrm{T} 4$ concentration but this was not statistically significant by $120 \mathrm{~min}$. In groups $I I I$ and $I V$ animals, there was no significant change in mean T4 concentration throughout the study. The $T 4$ concentrations were somewhat higher in the group IV animals than in the other groups; this difference presumably related to interassay variation in the RIA.

The changes in serum T3 concentration in newborns of groups $I-I V$ are presented in Figure 3. In all animals cord cutting was associated with a significant increase in serum T3. In group $I$ animals, serum $\mathrm{T} 3$ increased from $50 \pm 11 \mathrm{ng} / 100 \mathrm{ml}$ at delivery

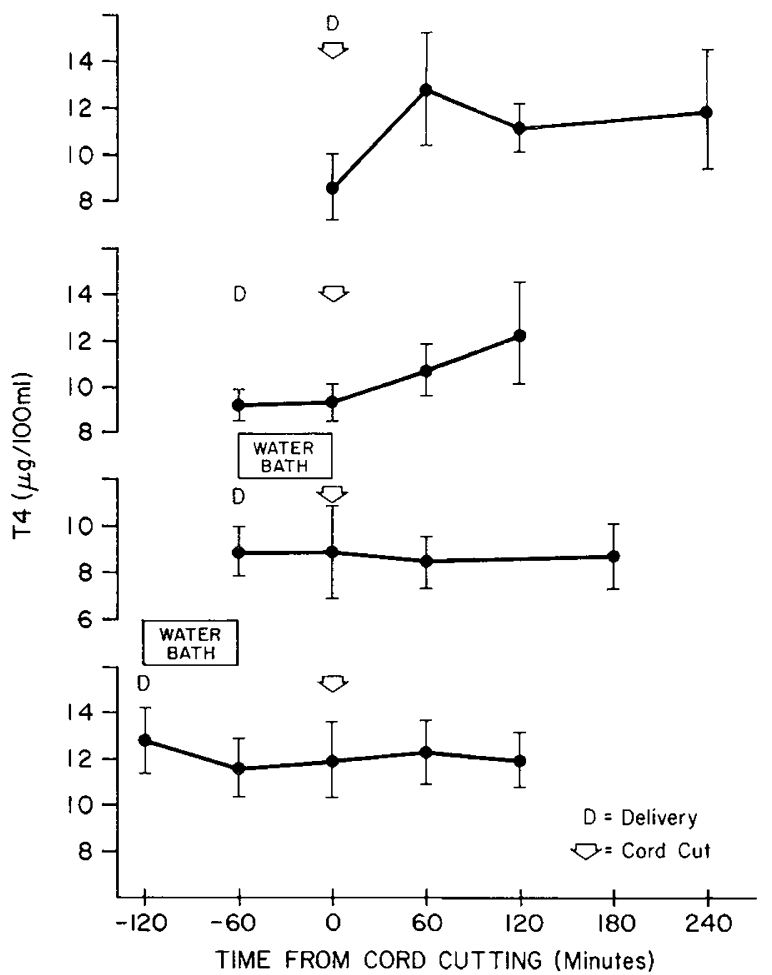

Fig. 2. Serum thyroxine (T4) concentrations (micrograms per $100 \mathrm{ml}$ ) in groups $I, I I, I I I$, and $I V$ animals. The solid circles $(-)$ represent the mean and the bars the SEM values. The results are displayed so that cord cutting represents zero time. Details for the several group protocols are explained in text.

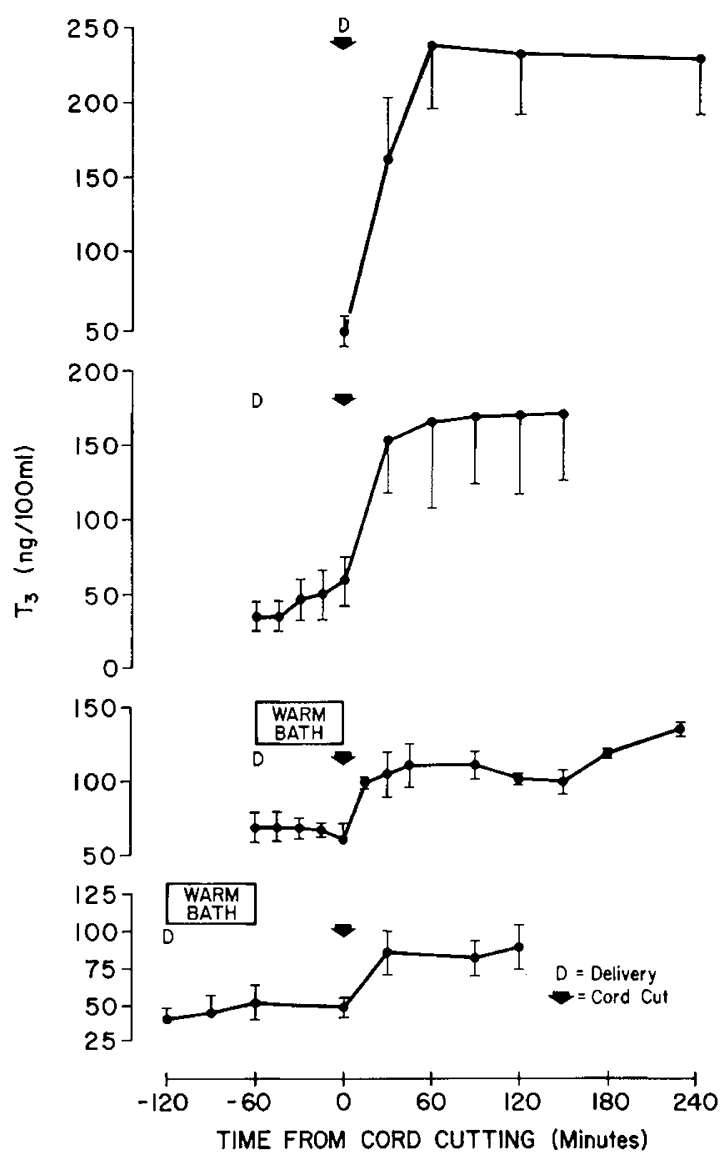

Fig. 3. Serum triiodothyronine $(T 3)$ concentration (nanograms per 100 $\mathrm{ml})$ data in groups $I, I I, I I I$, and $I V$ animals. The solid circles $(\bullet)$ represent the mean and the bars the SEM values. The results are displayed so that zero time in all groups represents cord cutting. Details of the several group protocols are explained in text.

to $167 \pm 36 \mathrm{ng} / 100 \mathrm{ml}$ by $30 \mathrm{~min}$, and to $242 \pm 43 \mathrm{ng} / 100 \mathrm{ml} 60$ min after delivery. In group $I I$ newborns, as long as the cord was intact, there was no increase in serum T3 concentration, but 90 min after delivery and $30 \mathrm{~min}$ after cord cutting, there was a marked rise (from $34 \pm 10 \mathrm{ng} / 100 \mathrm{ml}$.to $154 \pm 37 \mathrm{ng} / 100 \mathrm{ml}$ ); the mean T3 increased further to $165 \pm 58 \mathrm{ng} / 100 \mathrm{ml} 120 \mathrm{~min}$ after cord cutting. In group III newborns, mean serum T3 was unchanged as long as the animals were in the water bath. After delivery from the water bath and after cord cutting, there was a rise in T3 from a mean of $60 \pm 12 \mathrm{ng} / 100 \mathrm{ml}$ to $104 \pm 16 \mathrm{ng} / 100 \mathrm{ml}$ within $30 \mathrm{~min}$. In group $I V$ animals, the increase in serum T3 also was delayed until cord cutting, after which time serum T3 increased significantly (from $48 \pm 8 \mathrm{ng} / 100 \mathrm{ml}$ to level of $85 \pm 13 \mathrm{ng} / 100 \mathrm{ml}$ ).

The changes in FFA concentrations are depicted in Figure 4. In group I lambs, there was a marked rise in mean (and SEM) FFA, from $245 \pm 95 \mu \mathrm{Eq} /$ liter to $744 \pm 187 \mu \mathrm{Eq} /$ liter within $60 \mathrm{~min}$ of delivery and cord cutting. In group II animals, as long as the cord was intact, there was no significant rise in mean serum FFA concentration. However, $30 \mathrm{~min}$ after cord cutting, there was marked increase in mean FFA (from $280 \pm 60 \mu \mathrm{Eq} /$ liter to $748 \pm$ $90 \mu \mathrm{Eq} /$ liter). In group III animals, the mean FFA level remained unchanged until $30 \mathrm{~min}$ after delivery from the water bath and cord cutting. By that time, the mean concentration had increased from $213 \pm 12 \mu \mathrm{Eq} /$ liter to $402 \pm 123 \mu \mathrm{Eq} /$ liter. In group $I V$ newborns, the mean serum FFA level also remained unchanged as long as the lambs were in the water bath and during the 60 min after delivery from the water bath before the cord was cut. At the time of cord cutting, the mean serum FFA concentration $(210 \pm 52 \mu \mathrm{Eq} /$ liter $)$ was similar to that at the time of delivery from the water bath (188 


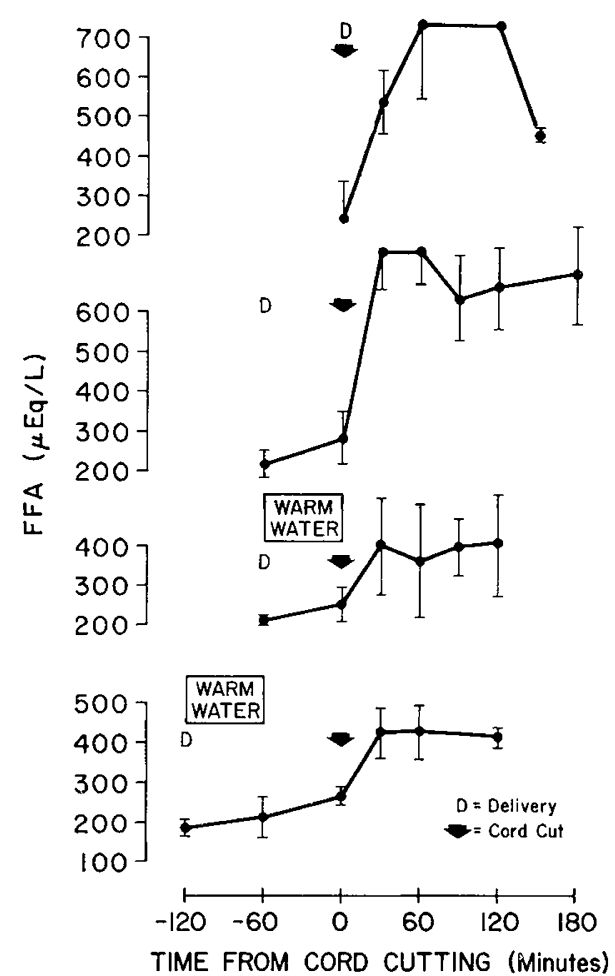

Fig. 4. Serum free fatty acid $(F F A)$ concentrations (microequivalents per liter) in groups $I, I I, I I I$, and $I V$ animals. The solid circles $(\bullet)$ represent the mean and bars the SEM values. The results are displayed so that zero time in all groups represents cord cutting. Details of the several group protocols are explained in text.

$\pm 17 \mu \mathrm{Eq}$ /liter). However, $30 \mathrm{~min}$ after cord cutting there was a significant rise in the mean FFA level (to $422 \pm 65 \mu \mathrm{Eq} /$ liter).

Figure 5 shows the serum TSH responses to parturition in groups $I$ and $I I$ animals during the first 120 min after delivery. The baseline cord blood values were similar in the two groups $(4.7 \pm$ 0.7 and $5.3 \pm 0.9 \mu \mathrm{U} / \mathrm{ml}$, respectively). The TSH surge was similar in timing and extent in both groups of animals in spite of the fact that cord cutting was delayed in group II animals. TSH values in group III animals were unchanged, averaging $4.4 \pm 0.8$ $\mathrm{U} / \mathrm{ml}$ during the period of water bath immersion.

Figure 6 shows the linear correlation between serum T3 or FFA concentrations $60 \mathrm{~min}$ after cord cutting and the minimum rectal temperature which usually occurred within 30 min after cord cutting. The respective correlation coefficients $(r=0.71$ and $r=$ $0.53)$ were significant $(P<0.005)$.

Blood gas and $\mathrm{pH}$ values were monitored in all of the study groups as indicated under Materials and Methods, and were stable in all groups during the periods of water bath immersion. During the 60 -min interval between exposure to the extrauterine environment and delayed cord cutting in groups $I I, I V, V$, and $V I$ animals, $\mathrm{pO}_{2}$ values also remained relatively stable in the range of 10-23 $\mathrm{mm} \mathrm{Hg}$. Some acidosis was observed. Table 1 summarizes representative data in the group II newborns. There was a gradual fall in mean (and SEM) blood pH from $7.34 \pm 0.02$ at birth to 7.29 \pm 0.01 at the time of cord cutting and a further significant fall was observed during the first $30 \mathrm{~min}$ after cord cutting (to $7.22 \pm 0.01$ ). By 120 min after cord cutting the $\mathrm{pH}$ value had risen almost to the initial value. The mean blood $\mathrm{pO}_{2}$ was stable before cord cutting, which was followed by a marked increase in $\mathrm{pO}_{2}$, from a low of $16.3 \pm 2.5 \mathrm{~mm} \mathrm{Hg}$ to $31 \pm 1.5 \mathrm{~mm} \mathrm{Hg}$ at $30 \mathrm{~min}$. The change in mean $\mathrm{pCO}_{2}$ was not significant (from $55 \pm 6 \mathrm{~mm} \mathrm{Hg}$ at delivery to $47 \pm 1 \mathrm{~mm} \mathrm{Hg}$ at the time of cord cutting and $52 \pm 3 \mathrm{~mm} \mathrm{Hg} 30$ min later). The mean baseline $\mathrm{pO}_{2}$ values of about $16 \mathrm{~mm} \mathrm{Hg}$ are somewhat lower than the mean values of about $25 \mathrm{~mm} \mathrm{Hg}$ recently reported by Comline and Silver (8), but were similar to values reported previously from our laboratory for newly catheterized fetuses maintained in utero (15). Mean arterial $\mathrm{pO}_{2}$ in the chronically catheterized fetal sheep in our laboratories is $19.5 \pm$ $1.0 \mathrm{~mm} \mathrm{Hg} \mathrm{5-15}$ days postcatheterization; the mean value before 5 days is $14 \pm 1.4 \mathrm{~mm} \mathrm{Hg}(15)$. The twofold increase in $\mathrm{pO}_{2}$ with cord cutting is similar to that observed by Comline and Silver (8).

Figure 7 depicts the results of the TRH injections in group $V$ lambs. There was a fall in mean rectal temperature from $40^{\circ}$ to $36^{\circ}$ during the first hour after removal from the water bath and shivering was observed within 10-35 minutes. There was no significant increase in mean serum T4 or T3 levels during the first $60 \mathrm{~min}$ after TRH. After cutting the cord, there was a significant rise in T3 (from a mean of $78 \pm 20 \mathrm{ng} / 100 \mathrm{ml}$ to a mean of $161 \pm$ $22 \mathrm{ng} / 100 \mathrm{ml}$ within $30 \mathrm{~min})$. The mean serum T3 concentration 5 $\mathrm{hr}$ after TRH injection ( $4 \mathrm{hr}$ after cord cutting) was $336 \pm 46$ $\mathrm{ng} / 100 \mathrm{ml}$. The increase in serum T4 was significant $3 \mathrm{hr}$ after TRH administration (from $10.3 \pm 0.8$ to $14 \pm 1.1$ ). As long as the animals were in the water bath and the cord was intact, there was no significant rise in mean serum FFA $(216 \pm 32 \mu \mathrm{Eq} /$ liter and $261 \pm 21 \mu \mathrm{Eq} /$ liter), but $60 \mathrm{~min}$ after cord cutting the FFA concentration was $515 \pm 109 \mu \mathrm{Eq} /$ liter.

The effects of $\mathrm{T} 3$ injection $(5 \mu \mathrm{g})$ in group $V I$ newborns are shown in Figure 8. Fifteen minutes after the T3 injection, the mean serum T3 concentration was $268 \pm 29 \mathrm{ng} / 100 \mathrm{ml}$, a value similar to the peak value $(240 \pm 43 \mathrm{ng} / 100 \mathrm{ml})$ in group I control animals. There was no significant change in T4 concentrations during the study. The increase in serum FFA concentration was significantly augmented over the response observed in group IV water bath control animals after cord cutting (Figure 4), and equaled the rise in FFA seen in the room air control animals of group $I$. The rise in rectal temperature paralleled the FFA response and was much more marked than that observed in the group IV water bath control lambs (Figure 1). All animals survived and managed to correct their hypothermia.

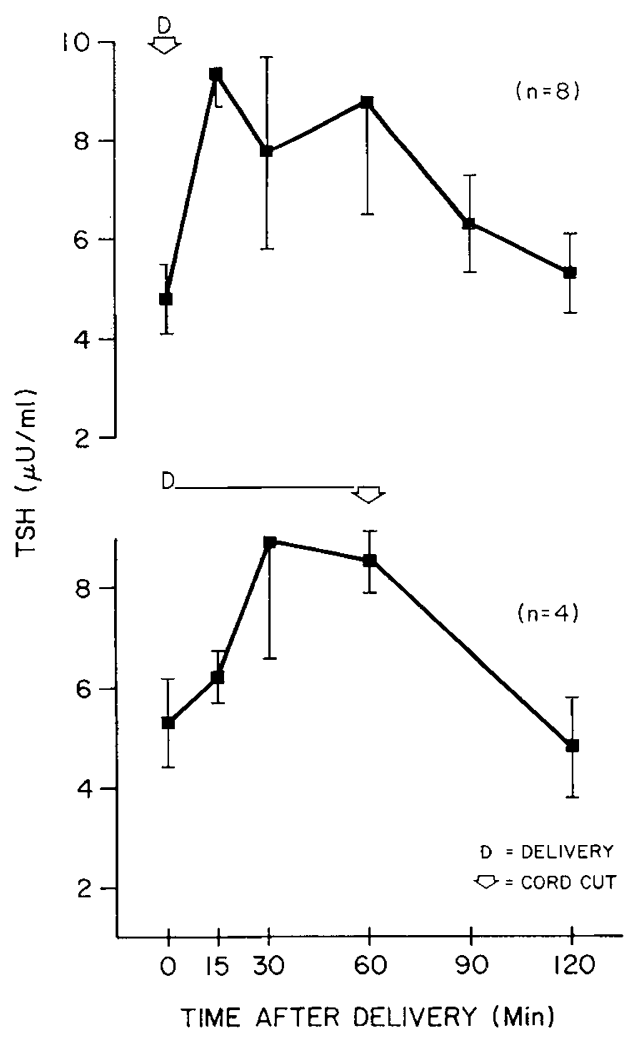

Fig. 5. Serum thyroid-stimulating hormone (TSH) values in groups $I$ and $I I$ animals during the first $120 \mathrm{~min}$ after delivery. Group $I$ animals are shown above and group $I I$ arimals below. Values are recorded as mean and SEM. 


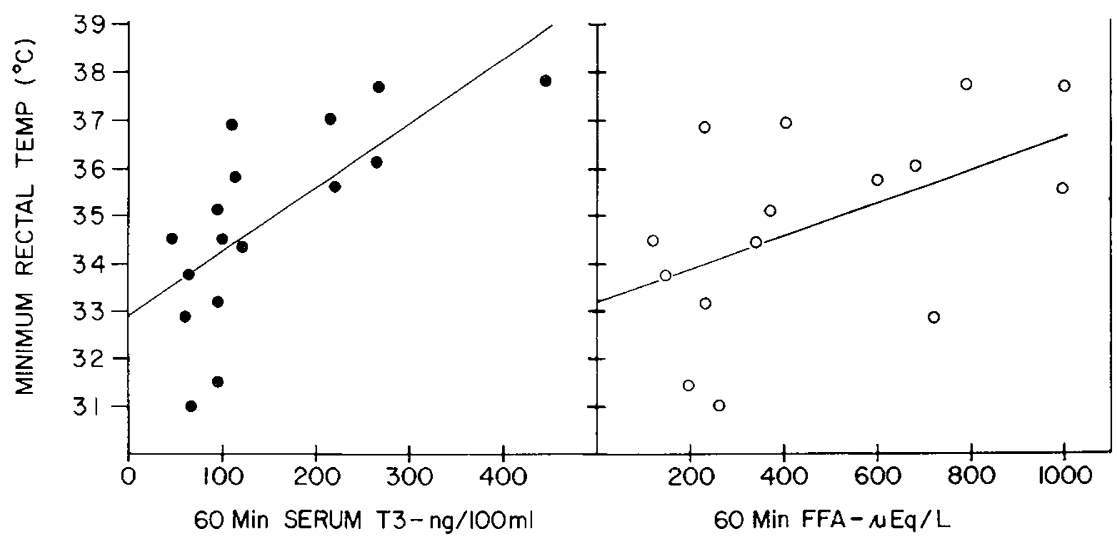

Fig. 6. Correlations between serum triiodothyronine (T3) (in nanograms per $100 \mathrm{ml}$ ) or free fatty acid $(F F A)$ in microequivalents per liter $60 \mathrm{~min}$ after cord cutting and minimal rectal temperature (usually occurring within $60 \mathrm{~min}$ after cord cutting). The respective correlation coeficients $(r=0.7 \mathrm{l}$ and $r=0.53)$ are statistically significant $(P<0.005)$.

Table 1. Changes in blood $\mathrm{pH}, \mathrm{pO}_{2}$, and $\mathrm{pCO} \mathrm{O}_{2}$ values before and after cord cutting in group II lambs

\begin{tabular}{rccc} 
Time & $\mathrm{pH}$ & $\mathrm{pO}_{2}$ & $\mathrm{pCO}_{2}$ \\
\hline-60 & $7.34 \pm 0.02$ & $13.4 \pm 0.9$ & $55 \pm 6$ \\
-30 & $7.30 \pm 0.03$ & $16.3 \pm 0.9$ & $52 \pm 5$ \\
0 & $7.29 \pm 0.01$ & $16.3 \pm 2.5$ & $47 \pm 1$ \\
30 & $7.22 \pm 0.01$ & $31.0 \pm 1.5$ & $52 \pm 3$ \\
60 & $7.29 \pm 0.03$ & $32.3 \pm 2.3$ & $49 \pm 2$ \\
90 & $7.28 \pm 0.03$ & $35.8 \pm 3.8$ & $48 \pm 2$ \\
120 & $7.32 \pm 0.01$ & $32.3 \pm 2.3$ & $49 \pm 2$
\end{tabular}

${ }^{1}$ Zero time represents cord cutting; values recorded as mean and SEM; $\mathrm{pO}_{2}$ and $\mathrm{pCO}_{2}$ values in $\mathrm{mm} \mathrm{Hg}$.

\section{DISCUSSION}

The present study indicates that the newborn lamb responds to parturition in a manner qualitatively similar to the human newborn. There is a TSH surge (Figure 5) which peaks at $30 \cdots 60$ $\min$ and falls thereafter to baseline within $2 \mathrm{hr}$. This response is not as marked or prolonged as that in the human neonate, but it is associated with a similar increase in $\mathrm{T} 3$ concentrations from very low cord blood levels to very high values within $60 \mathrm{~min}$ after birth (Figure 3; group I). During this time, there also is an increase in mean serum T4 concentrations (Fig. 2) but, as in the human newborn, this increase is less marked and more delayed (14). The marked increase in FFA which parallels the T3 response (Figure 4, group I) presumably is due to rapid mobilization from body fat stores, particularly brown fat $(10,27)$, as a result of increased catecholamine secretion. In addition, shivering was observed as early as $5 \mathrm{~min}$ after deiivery. These observations seemed compatible with the view that early cooling evokes the TSH surge and thyroid hormone responses in the newborn lamb.

To further test this hypothesis and to study the effect of parturition without hypothermia, we delivered group III newborn lambs into a warm water bath. Harned et al. (19), in an extensive study of initiation of breathing by cold stimulation, showed the newborn lambs fail to breathe when kept in a warm fluid environment. We, therefore, delivered the lambs into the warm water bath with the cord intact and the head covered with a surgical glove to prevent water aspiration. The function of the placenta was not impaired, enabling the lambs to survive adequately oxygenated and nourished in the water bath; $\mathrm{pH}$ and $\mathrm{pO}_{2}$ values were maintained essentially unchanged during this period. However, when removed from the water bath, all animals experienced rather marked hypothermia and the increase in mean T3 and FFA levels were obtunded relative to group I control newborns

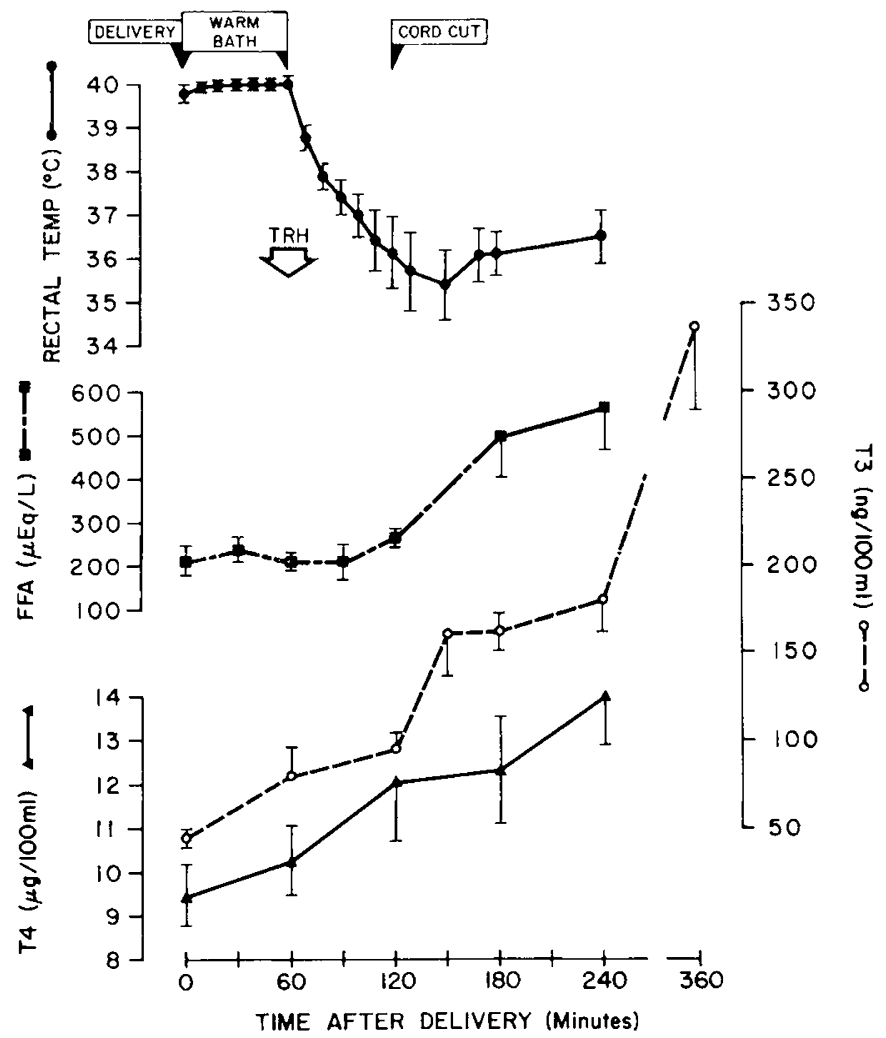

Fig. 7. Rectal temperature and serum free fatty aicd $(F F A)$, triiodothyronine (T3), and thyroxine (T4) concentration data in group $V$ animals. Thyrotropin-releasing hormone $(T R H), 250 \mu \mathrm{g}$, was injected $60 \mathrm{~min}$ after delivery at the time the animals were removed from the warm water bath. Cord cutting was delayed $60 \mathrm{~min}$ (120 min after delivery). See text for details.

(Figs. 3 and 4). Moreover, the hypothermia occurred in spite of marked shivering. In these animals the warming seemed to suppress both the catecholamine response (or its effect on FFA release) and T3 production. The reason for this is not clear.

The hypothermia might have occurred because of the relatively low $\mathrm{pO}_{2}$ values, even though these were similar to values in catheterized fetuses maintained in utero during the first 5 days (15). The increase in $\mathrm{O}_{2}$ subsequent to autonomous respiration (Table 1) may be essential for optimal extrauterine thermogenesis. Whatever the mechanisms of the hypothermia, however, these studies in group $I I I$ animals indicated clearly that the processes of parturition did not evoke the FFA and T3 responses; as long as the 


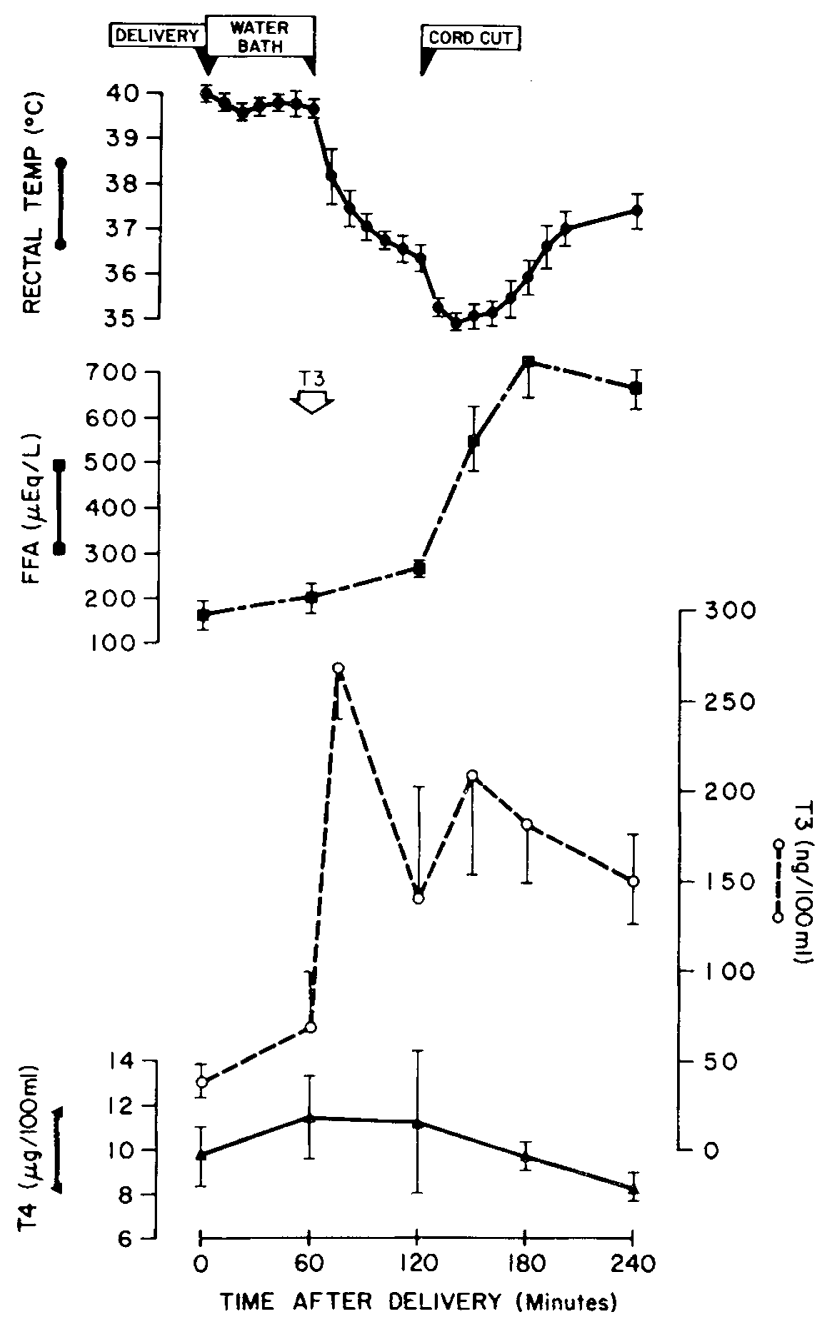

Fig. 8. Rectal temperature and serum free fatty acid $(F F A)$, triiodothyronine (T3), and thyroxine (T4) concentration data in group VI animals. Five micrograms of $T 3$ were injected at the time the animals were removed from the warm water bath. Cord cutting was delayed $60 \mathrm{~min}$ (120 min after delivery). See text for details.

lambs remained in the warm water bath, rectal temperature was maintained (Fig. 1) and there were no significant changes in the concentrations of T3, T4, or FFA (Figs. 2-4).

To control the effect of cord cutting, group IV animals were studied. In these animals, when cord cutting was delayed, there was a marked and prolonged hypothermia as in group III animals (Fig. 1). However, in spite of the hypothermia and in the presence of nearly normal $\mathrm{pH}$ and normal intrauterine $\mathrm{pO}_{2}$ values, serum $\mathrm{T} 3$ and FFA concentrations remained unchanged. Only after cutting the umbilical cord did serum FFA and T3 levels increase (Figs. 3 and 4). To confirm this effect, group $I I$ animals were studied. In these animals, also, delaying cord cutting provoked marked hypothermia and the increases in serum $\mathrm{T} 3$ and FFA occurred only after cord cutting (Figs. 3 and 4). However, in these animals, the increases in $\mathrm{T} 3$ and FFA concentrations were comparable with those observed in group I control animals.

The increases in serum FFA and T3 levels in these animals after cord cutting also were much more marked than could be accounted for by changes in blood flow or reduction in the volume of FFA or T3 distribution produced by eliminating the placenta. This is particularly true in group $I I$ animals. Assuming that production of T3 continues at the fetal rate of $1.5 \mu \mathrm{g} / \mathrm{kg} / 24 \mathrm{hr}$ (about $1 \mathrm{ng} / \mathrm{min}$ ) (13), a $50 \%$ reduction in T3 distribution space (from 5 to 2.5 liters) would be expected to increase serum T3 concentration less than 10 $\mathrm{ng} / 100 \mathrm{ml}$. Similar relative calculations can be made for FFA. Shivering was observed in all fetuses within 10-34 min of the onset of cooling and continued for prolonged periods; however, shivering did not prevent marked and progressive hypothermia (26).

Thus, these studies indicated that cord cutting, rather than hypothermia, is the stimulus to FFA and T3 production and thermogenesis in the newborn sheep. The mechanism is not yet clear. The hypothermia might have been the consequence of the relative hypoxia, even though $\mathrm{pO}_{2}$ values were comparable with those in catheterized fetuses maintained in utero (15) with reasonably normal metabolism. The FFA and $\Upsilon 3$ responses might require a critical threshold of $\mathrm{pO}_{2}$ available only after autonomous extrauterine respiration, in which case one might suggest that cord cutting triggers FFA and $\mathrm{T} 3$ production by increasing $\mathrm{pO}_{2}$ levels.

The extent of thermogenesis after cord cutting seems to be conditioned both by FFA and T3 levels. The inverse correlation between the degree of the hypothermia and the concentration of T3 or FFA 60 min after cord cutting (Fig. 6) suggests that both hormones influence thermogenesis significantly. This view is further supported by the results of the studies in group VI animals (Fig. 8). In these animals, the exogenous T3 injected at the time of delivery from the warm water bath produced a prompt increase in mean serum T3 comparable with that observed by cord cutting in group I control animals. Hypothermia occurred in spite of high T3 levels as long as the umbilical cord was intact, during a time when $\mathrm{pO}_{2}$ values were maintained at intrauterine levels of $12-22 \mathrm{~mm} \mathrm{Hg}$. At the time of cord cutting, the increase in FFA and the degree of thermogenesis were much more marked than in the group III water bath control animals not given T3. Actually, the rate of increase in rectal temperature in these animals was similar to that in group I control animals who had not been maintained in a water bath. These results suggest that both FFA mobilization and nonshivering thermogenesis are augmented by $\mathrm{T} 3$ in the newborn lamb.

Van Duyne et al. (27) have shown in newborn lambs that the increase in FFA after birth is due to augmented mobilization of free fatty acid into the blood and that this mobilization can be prevented by blocking transmission of autonomic ganglia with hexamethonium. Thus, the stimulus for FFA release appears to be increased autonomic nervous system activity. The fact that norepinephrine infusion will increase circulating FFA levels in the newborn $(3,4,25)$ further supports this hypothesis. Norepinephrine infusion also increases nonshivering thermogenesis in the newborn, suggesting that both the thermogenesis and FFA release result from autonomic nervous system stimulation and catecholamine release $(2,20,21)$.

The data in Figure 5 indicate that the neonatal TSH surge occurs in response to parturition, whether or not the umbilical cord is cut. By contrast, Figure 3 indicates that the T3 response occurs only after cord cutting. Thus the TSH and early $\mathrm{T} 3$ responses can be dissociated. Other data also suggests that the early T3 response is not TSH dependent. TRH injection at the time of delivery from the water bath (group $V$ animals, Figure 7) failed to increase serum $\mathrm{T} 3$ or T4 levels during the first $60 \mathrm{~min}$. Rather, a delayed response was observed similar to that observed in the newborn lamb at 2-4 days. The TRH was biologically effective, because the same dose of the same preparation increased serum TSH in two euthyroid adult sheep. In addition, the TRH did evoke marked increases in serum T4 and T3 by $4 \mathrm{hr}$ (Figure 7), as is the case in adult sheep and in adult human subjects. Thus, the early $(60 \mathrm{~min})$ increase in serum T3 concentration after cord cutting does not appear to be due to a TRH and TSH-mediated increase in thyroidal T3 secretion. Rather, the present results suggest that cord cutting, at least in the sheep, in some way augments $\mathrm{T} 3$ conversion from T4. In support of this view we have reported preliminary evidence suggesting that tyrosine hydroxylase, the rate-limiting enzyme in catecholamine synthesis, mediates the early increase in serum T3 via monodeiodination of T4 (23). Thus, the FFA increment, the thermogenic response, and the early increase in T3 production in the newborn all may be mediated by stimulation of autonomic nervous system activity.

Increased T3 secretion probably also is involved in the increase 
in T3 levels in the newborn. A significant increase in serum T4 values was observed in the control animals in the present study during the first hour of life (Fig. 2); significant release of prelabeled thyroid hormone has been reported in the newborn lamb during the first $48 \mathrm{hr}$ after birth, as well as blockade of this release with stable iodine (5); and significant increase in serum T4 concentrations is characteristic of the newborn human infant during the first $24-48 \mathrm{hr}$ of extra uterine life $(1,2,14,17,18)$. Thus, two mechanisms of thyroid hormone response to parturition seem to be operative: (1) an increase in T3 production largely derived from augmented monodeiodination of $\mathrm{T} 4$ in peripheral tissues, and (2) stimulation of thyroid hormone secretion. The increased $\mathrm{T} 4$ deiodination increases serum $\mathrm{T} 3$ concentrations within 1-2 hr. Increased thyroid hormone secretion results in a more gradual increase in serum T4 and T3 levels with peak values observed at $24-48 \mathrm{hr}$.

It is of interest that maintaining the newborn lamb in a $39^{\circ}$ water bath for $60 \mathrm{~min}$ significantly inhibits the FFA, T3, and thermogenic responses to cord cutting (Figs. 1, 3, and 4). In these animals blood $\mathrm{pH}$ and $\mathrm{pO}_{2}$ were similar to values in catheterized fetuses maintained in utero (15). Moreover, respiratory movements in these animals did not occur until after cord cutting as in the other groups of newborns, and $30 \mathrm{~min}$ after cord cutting their blood $\mathrm{pO}_{2}$ values were similar to $\mathrm{pO}_{2}$ values in newborns not maintained in the water bath. Thus, these observations indicate that the warming does not provoke hypoxia and suggests that the maneuver in some way inhibits autonomic responsiveness, although the mechanism is not clear.

\section{SUMMARY}

The temperature, FFA, and T3 responses to parturition have been studied in control newborn lambs and in lambs in which extrauterine cooling was prevented by maintenance in a $39^{\circ}$ water bath and/or cord cutting was delayed $60 \mathrm{~min}$ after delivery into room air. The T3 and FFA responses in control animals were marked and peaked at $60 \mathrm{~min}$ after delivery. The fall in rectal temperature was transient and minimal in these animals. Warming in a water bath prevented the hypothermia and the FFA and T3 responses to delivery. In each instance in which cord cutting was delayed, progressive hypothermia was observed and the FFA and T3 responses followed the delayed cord cutting which also stimulated nonshivering thermogenesis and reversed the trend of falling rectal temperature.

The newborn TSH surge occurred whether or not the umbilical cord was cut. Moreover, TRH did not increase serum T3 during the first $60 \mathrm{~min}$, suggesting that the $\mathrm{T} 3$ increase was not due to stimulation by TSH. T3 did not stimulate FFA release or thermogenesis directly, but augmented both responses to cord cutting. These results indicate that umbilical cord cutting, rather than cooling, stimulates FFA release, $\mathrm{T} 3$ production, and nonshivering thermogenesis in the newborn lamb. More over, the early ( 60 $\mathrm{min}$ ) T3 response appears to represent increased conversion of T4 to T3 rather than TRH-mediated thyroidal T3 secretion. Finally, both FFA and T3 play a role in mediating newborn nonshivering thermogenesis.

\section{REFERENCES AND NOTES}

1. Abuid, J. L., Klein, A. H., Foley, T. P., Jr., and Larsen, P. R.: Total and free triiodothyronine and thyroxine in early infancy. J. Clin. Endocrinol. Metab., 39: 263 (1974).
2. Abuid, J. L., Stinson, D. A., and Larsen, P. R.: Serum triiodothyronine and thyroxine in the neonate and the acute increases in these hormones following delivery. J. Clin. Invest., 52: 1195 (1973).

3. Alexander, G.: The effect of adrenalin and noradrenaline on metabolic rate in young lambs. Biol. Neonate, 14: 97 (1969).

4. Alexander, G., Mills, S. C., and Scott, T. W.: Changes in plasma glucose, lactate and free fatty acids in lambs during summit metabolism and treatment with catecholamines. J. Physiol., 198: 277 (1968).

5. Burman, K. D., Fox, J. D., Earll, J. M., and Wartofsky, L.: Sources of increasing serum triiodothyronine (T3) in newborn sheep, p. $\Upsilon-21$. Program of the 50th Meeting of the American Thyroid Association, 1974.

6. Chopra, I. J.: A radioimmunoassay for measurement of thyroxine in unextracted serum. J. Clin. Endocrinol. Metab., 34: 938 (1973).

7. Chopra, I. J., Ho, R. S., and Lam, R. W.: An improved radioimmunoassay of triiodothyronine in serum: Its application to clinical and physiologic studies. J. Lab. Clin. Med., 80: 729 (1972).

8. Comline, R. W., and Silver, M.: The composition of foetal and maternal blood during parturition in the ewe. J. Physiol. (London), 222: 233 (1972).

9. Czernichow, P., Greenberg, A. H., Tyson, J., and Blizzard, R. M.: Thyroid function studied in paired maternal cord sera and sequential observations of thyrotropic hormone release during the first 72 hours of life. Pediat. Res., $5: 53$ (1971).

10. Dawkins, M. J.R., and Hull, D.: Brown adipose tissue and the response of newborn rabbits to cold. J. Physiol. (London), 172: 216 (1964).

11. Dawkins, M. J. R., and Scopes, J.: Non-shivering thermogenesis and brown adipose tissue in the human newborn infant. Nature, 206: 201 (1965).

12. Dole, V. P.: A relation between nonesterified fatty acids in plasma and the metabolism of glucose. J. Clin. Invest., 35: 150 (1956).

13. Dussault, J. H., Hobel, C. J., DiStefano, J. J., III, Erenberg, A., and Fisher, D. A.: Triiodothyronine turnover in maternal and fetal sheep. Endocrinology, 90: 1301 (1972)

14. Erenberg, A., Phelps, D., Lam, R., and Fisher, D. A.: Total and free thyroid hormone concentrations in the neonatal period. Pediatrics, 53:211 (1974).

15. Fiser, R. H., Erenberg, A., Fisher, D. A., and Oh, W.: Blood gas and pH changes during glucose infusion in the fetal sheep. Amer. J. Obstet. Gynecol., 115: 942 (1973).

16. Fisher, D. A., and Makoski, E.: Temperature adaptation of the newborn to the extrauterine environment. J. Lancet, 86: 85 (1966).

17. Fisher, D. A., Oddie, T. H., and Makoski, E.: The influence of environmental temperature on thyroid, adrenal, and water metabolism in the newborn human infant. Pediatrics, 37: 583 (1966).

18. Fisher, D. A., and Odell, W. D.: Açute release of thyrotopin in the newborn. J. Clin. Invest., 48: 1670 (1969).

19. Harned, H. S., Jr., and Ferreiro, J.: Initiation of breathing by cold stimulation: Effects of change in ambient temperature on respiratory activity of the full-term fetal lamb. J. Pediat., 83: 663 (1973).

20. Karlberg, P., Moore, R. E., and Oliver, T. K.. Jr.: The thermogenic response of the newborn infant to noradrenaline. Acta Paediat. (Uppsala) Suppl., 140:53 (1963).

21. Karlberg, P., Moore, R. E., and Oliver, T. K., Jr.: Thermogenic and cardiovascular responses of the newborn baby to noradrenaline. Acta Paediat. (Uppsala) 54: $225(1965)$.

22. LeBlanc, J., and Villemaire, A.: Thyroxine and noradrenaline on noradrenaline sensitivity, cold resistance, and brown fat. Amer. J. Physiol., 218: 1742 (1970).

23. Sack, J., and Fisher, D. A.: Tyrosine hydroxylase mediates the $T 3$ and thermogenic responses to parturition. Clin. Res., 23: 161A (1975).

24. Swanson, H. E.: Interrelationships between thyroxine and adrenalin in the regulation of oxygen consumption in the albino rat. Endocrinology, 59: 217 (1956).

25. Schiff, D., Stern, L., and Leduc, $\mathbf{J}$ : Chemical thermogenesis in newborn infants: Catecholamine excretion and the plasma non-esterified fatty acid response to cold exposure. Pediatrics, 37: 577 (1966).

26. Thompson, G. E., and Jenkinson, D. McE.: Non-shivering thermogenesis in the newborn lamb. Can. J. Physiol. Pharmacol., 47: 249 (1969).

27. VanDuyne, C., Parker, H. R., Holm, L. W., Hirai, T., and Gallager, J.: Metabolism of free fatty acids during perinatal life of lambs. Amer. J. Obstet. Gynecol., 91: 277 (1965)

28. This research was supported by Public Health Service Grant no. HD-04270 from the National Institute of Child Health and Human Development, National Institutes of Health, Bethesda, Md.

29. Requests for reprints should be addressed to: D. A. Fisher, M.D., Perinatology, Harbor General Hospital, 1000 West Carson St., Torrance, Calif. 90509 (USA).

30. Accepted for publication October 29, 1975. 